Full length article

\title{
Functionally significant polymorphisms of ESR1and PGR and risk of intrauterine growth restriction in population of Central Russia
}

\author{
Oleg Golovchenko ${ }^{a}$, Maria Abramova ${ }^{a}$, Irina Ponomarenko ${ }^{a}$, Evgeny Reshetnikov ${ }^{a, *}$, \\ Inna Aristova ${ }^{\mathrm{a}}$, Alexey Polonikov ${ }^{\mathrm{b}}$, Volodymyr Dvornyk ${ }^{\mathrm{c}}$, Mikhail Churnosov ${ }^{\mathrm{a}}$ \\ a Department of Medical Biological Disciplines, Belgorod State University, 308015 Belgorod, Russia \\ b Department of Biology, Medical Genetics and Ecology, Kursk State Medical University, 305041 Kursk, Russia \\ ' Department of Life Sciences, College of Science and General Studies, Alfaisal University, 11533 Riyadh, Saudi Arabia
}

\section{A R T I C L E I N F O}

\section{Article history:}

Received 7 May 2020

Received in revised form 21 July 2020

Accepted 24 July 2020

\section{Keywords:}

ESR1

PGR

Intrauterine growth restriction

Pregnancy

Single nucleotide polymorphism

\begin{abstract}
A B S T R A C T
Objective: This study aimed to investigate the role ofESR1 and PGR gene polymorphisms in development of intrauterine growth restriction (IUGR) among Russian women in Central Russia.

Study design: This case-control study recruited a total of 520 women in the third trimester of pregnancy, including 196 IUGR patients and 324 controls. The participants were unrelated women of self-reported Russian ethnicity. Participants were genotyped at 4 functionally significant polymorphisms of theESR1 (rs2234693, rs9340799) and the PGR (rs484389, rs1042838) genes. The association analysis was performed using logistic regression. Two polymorphisms, which were associated with IUGR, and 26 polymorphisms linked to them $\left(r^{2} \geq 0.6\right)$ were analyzed for their functional significance in silico.

Results: Haplotype TG of loci rs2234693-rs9340799ESR1 (OR $\left.=1.94, \mathrm{p}_{\mathrm{perm}}=0.006\right)$ was associated with an increased risk of IUGR. Allele T of rs2234693 decreases expression of ESR1 in thyroid gland, allele T of rs2234693 and allele $G$ of rs9340799 increase affinity to eight transcription factors (AP-4, HEN1, E2A, LBP1, RP58, LUN, Ets and Hand). The loci that are linked $\left(r^{2} \geq 0.6\right)$ to the IUGR-associated SNPs, have the cis-eQTL value (expression ESR1 in thyroid gland) and showed their regulatory effects in organs and tissues related to pathogenesis of IUGR.

Conclusion: Haplotype TG defined by polymorphisms rs2234693-rs9340799 of theESR1 gene is associated with the development of IUGR in Russian women from Central Russia.
\end{abstract}

(c) 2020 Elsevier B.V. All rights reserved.

\section{Introduction}

Intrauterine growth restriction (IUGR) is a condition when the rate of fetal growth is lower than expected for the gender and race of the fetus [1,2]. IUGR usually results from innate reduced growth potential or multiple adverse effects on the fetus. The "normal" neonate has birth weight between the 10th and 90th percentile for the given gestational age, race and gender with no sign of growth retardation and malnutrition [1]. An estimated fetal weight or abdominal circumference of less than the 10th centile for the population at a given gestational age was traditionally considered highly suggestive of IUGR [3].

The worldwide prevalence of IUGR is estimated between $5 \%$ and $10 \%$ of all pregnancies [4]. It may strongly affect the newborn's short- and long-term health [5]. For affected infants, the health

\footnotetext{
${ }^{*}$ Corresponding author at: 85, Pobedy St., Belgorod State Universite, Department of Medical Biological Disciplines, Belgorod 308015, Russia.

E-mail address: reshetnikov@bsu.edu.ru (E. Reshetnikov).
}

complications at delivery may include hypothermia, hyper- or hypoglycemia, persistent pulmonary hypertension, polycythemia, pulmonary hemorrhage, intrapartum asphyxia and stillbirth [1]. Since IUGR often results in preterm birth, various prematurityassociated multisystem diseases, such as impaired cognitive and motor development or/and physical growth may contribute to the intermediate and long-term health complications in IUGR newborns [5]. Moreover, an impaired fetal growth can increase a risk for certain diseases later in life, such as metabolic syndrome, type 2 diabetes mellitus, obesity, dyslipidemia, cardiovascular diseases and others [6,7].

The mechanisms underlying IUGR remain unclear, since there is much heterogeneity of disease etiology. In general, IUGR has been associated with 1) fetal etiologies, such as genetic abnormalities (chromosomal abnormalities, syndromes,), 2) maternal factors (persistent hypoxia or undernutrition, vascular disease, and toxins), and 3) placental etiologies [8,9]. It is thought that $40 \%$ of birth weight is ascribable to genetic factors, whereas the other $60 \%$ is due to fetal environmental contributions [7]. Evidence from variance components analyses and monogenic human models [10] shows 
that birth weight variation is influenced both by genotypes inherited by the fetus and by maternal genotypes that influence the intrauterine environment [11].

Maternal genotypes determine maternal phenotypes, which may affect growth of the fetus, such as circulating levels of various metabolic factors (e.g., glucose, hormones, etc.) or/and transfer of these and other nutrients through the placenta. Such maternal environmental effects underlain by maternal genotype may affect fetal growth independently from the effects of respective genetic variants that are inherited by the fetus directly from the mother [12].

This study was aimed to analyze a role of polymorphisms of the ESR1 and PGR genes in the development of IUGR among Russian women from Central Russia.

\section{Material and methods}

\section{Study subjects}

Between 2013 and 2017, 520 unrelated women in the third trimester of pregnancy were enrolled in the study. The ethical approval was obtained from the Regional Ethics Committee of Belgorod State University. All individuals gave their written informed consent prior to entering the study. The participants were examined in the perinatal center of the Saint Joasaph Belgorod Regional Clinical Hospital.

When recruiting the participants, the following inclusion criteria were applied: Russian ethnicity (self-reported), birthplace in Central Russia [13], and singleton pregnancy. Patients with pre-eclampsia, congenital malformations of internal genitals, anomalies of placental location, uterine fibroids, self-declared non-Russian descent or a birthplace outside of Central Russia, isosensitization of $\mathrm{Rh}$ factor or ABO blood group systems were not enrolled. IUGR of varying severity was diagnosed in 196 participants. The diagnosis of IUGR was based on clinical data, growth and weight parameters after the birth and ultrasound fetometry (TOSHIBA XARIO SSA-660A) (as described elsewhere, [14]). Based on the differences between fetometric data and nomograms, three degrees of IUGR were defined: the first corresponded to the reduction of the estimated gestational ages from the standard ones by 2 weeks; the second - by 3-4 weeks; and the third - by more than 4 weeks [15]. The first-degree IUGR was revealed in 105 patients (53.57\%), second-degree in 77 patients (39.28\%) and third-degree in 14 patients ( $7.14 \%)$. Women without IUGR were controls (324 in total).

\section{DNA isolation and genotyping assay}

Approximately 4-5 $\mathrm{ml}$ blood sample from each participant was collected in vacutainer tubes (Vacutainer ${ }^{\mathbb{R}}$ ). DNA was extracted from whole blood by phenol-chloroform method and then checked for quality (as described earlier, [16]).

Based on the significant regulatory potential, in total four SNPs in ESR1 (rs2234693, rs9340799) and PGR (rs484389, rs1042838) genes were selected for the analysis [17]. These SNPs are located in a region of regulatory motifs and have impact on gene expression level (Table 1) (determined using the online tools HaploReg, v4.1 update 05.11.2015, https://pubs.broadinstitute.org/mammals/haploreg/haploreg.php).

Genotyping for all the polymorphisms was done using the MALDI-TOF mass spectrometry iPLEX platform (Agena Bioscience Inc, San Diego, CA). Genotyping blind replicates were included to ensure quality control. The repeatability test for $5 \%$ of randomly selected samples was performed, yielded $100 \%$ reproducibility.

\section{Statistical analysis}

Hardy-Weinberg equilibrium was assessed, based on the determined frequencies of genotypes and by using the chi-square test. The logistic regression method was used to analyze associations of the SNPs with IUGR assuming additive (i.e., comparison of all genotypes, e.g., TT vs TC vs CC), recessive (CC vs TC/TT, where $\mathrm{C}$ is a minor allele) and dominant (CC/TC vs TT, where $C$ is a minor allele) genetic models with adjustment for covariates (BMI and age at menarche as quantitative variables (value of the trait), and history of medical abortion as qualitative variables (yes/no)) (Table 2). The adaptive permutation test was applied to adjust for multiple comparisons [18]. The PLINK v. 2.050 software (available at http://zzz.bwh.harvard.edu/plink/) was used to perform the association analyses.

\section{Functional SNPS}

The genetic variants associated with IUGR and SNPs strongly linked to them were studied for their functional significance (regulatory potential and eQTLs). SNPs in strong linkage disequilibrium (LD) $\left(r^{2} \geq 0.6\right)$ with the IUGR-associated ones were identified using HaploReg (v4.1) (http://archive.broadinstitute. org/mammals/haploreg/haploreg.php). The data of the European population from the 1000 Genomes Project Phase was used to estimate linkage disequilibrium.

The regulatory potential of the candidate SNPs for IUGR was analyzed in silico using HaploReg (v4.1). The affinity between the factor-binding site of the reference (ref) and alternative (alt) alleles of a locus and transcription factors was estimated as a difference between the LOD scores of the alleles: $\Delta$ LOD = LOD (alt) - LOD (ref) [19]. A negative value indicates the increased affinity of this motif by the reference allele, while a positive value suggests the respective increase for the alternative allele.

\section{Table 1}

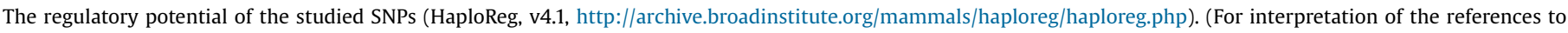
colour in this table, the reader is referred to the web version of this article.)

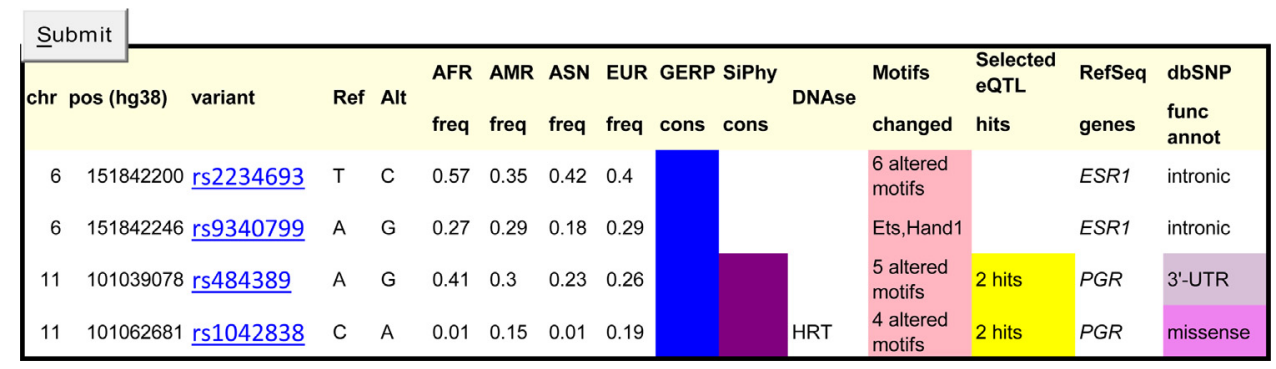


Table 2

Phenotypic characteristics of the study participants.

\begin{tabular}{|c|c|c|c|}
\hline Parameters & IUGR patients, n (\%) & Controls, n (\%) & $\mathrm{p}$ \\
\hline$N$ & 196 & 324 & - \\
\hline Age, years (min-max) & $26.63 \pm 4.41(16.0-41.0)$ & $26.18 \pm 4.98(18.0-41.0)$ & 0.07 \\
\hline BMI, $\mathrm{kg} / \mathrm{m} 2$ & $22.69 \pm 3.39$ & $23.72 \pm 3.61$ & 0.001 \\
\hline \multicolumn{4}{|l|}{ Age at menarche and menstrual cycle } \\
\hline Age at menarche, years & $12.77 \pm 1.10$ & $12.54 \pm 1.02$ & 0.01 \\
\hline Duration of bleeding menstrual (mean, days) & $5.05 \pm 0.73$ & $5.03 \pm 0.80$ & 0.76 \\
\hline Menstrual cycle length (mean, days) & $28.56 \pm 1.95$ & $28.32 \pm 1.62$ & 0.33 \\
\hline \multicolumn{4}{|l|}{ Gynecological pathologies } \\
\hline History of medical abortion & $32.14(63)$ & $22.53(73)$ & 0.02 \\
\hline History of infertility & $1.53(3)$ & $2.16(7)$ & 0.86 \\
\hline History of miscarriage (total) & $15.82(31)$ & $13.89(45)$ & 0.63 \\
\hline Miscarriage in first trimester & $10.20(20)$ & $8.02(26)$ & 0.49 \\
\hline Pregnancy loss in first trimester & $3.06(6)$ & $3.74(12)$ & 0.89 \\
\hline Ectopic pregnancy & $2.04(4)$ & $3.09(10)$ & 0.66 \\
\hline History of disorders of the menstrual cycle & $7.14(14)$ & $8.02(26)$ & 0.84 \\
\hline History of pelvic inflammatory disease & $15.82(31)$ & $13.89(45)$ & 0.63 \\
\hline Intrauterine infection during pregnancy & $28.06(55)$ & $25.93(84)$ & 0.66 \\
\hline Antenatal intrauterine fetal death & $1.53(3)$ & $0(0)$ & 0.10 \\
\hline \multicolumn{4}{|l|}{ Somatic pathologies } \\
\hline Essential hypertension & $27.04(53)$ & $20.06(65)$ & 0.08 \\
\hline Arterial hypotension & $2.55(5)$ & $2.47(8)$ & 1.00 \\
\hline Chronic pyelonephritis & $20.92(41)$ & $14.81(48)$ & 0.09 \\
\hline Obesity & $8.67(17)$ & $10.49(34)$ & 0.60 \\
\hline Varicose veins & $3.57(7)$ & $1.54(5)$ & 0.23 \\
\hline Endocrine disorders & $7.65(15)$ & $6.17(20)$ & 0.63 \\
\hline Chronic gastroduodenitis & $4.08(8)$ & $2.47(8)$ & 0.44 \\
\hline Nervous system pathology & $0.05(1)$ & $0(0)$ & 0.80 \\
\hline
\end{tabular}

GTExportal data (http://www.gtexportal.org/) as of 10.12 .2017 (Release V7 updated on 09/05/2017) (dbGaP Accession phs000424. v7.p2) was used to estimate an effect of the IUGR candidate SNPs on gene expression level (cis- and trans-eQTL). The False Discovery Rate (FDR) $\leq 0.05$ was applied to determine significant eQTLs. Linear regression coefficient $(\beta)$ that indicates a change of the normalized gene expression per a single polymorphic variant was used to estimate effect of an allelic variant on the gene expression.

\section{Results}

The phenotypic characteristics of the case and control groups are presented in Table 2. The IUGR patients had lower BMI $(p=0.001)$, ) higher rates of history of medical abortion $(p=0.02)$ and later menarche at age $(\mathrm{p}=0.01)$ as compared to the controls (Table 2). Therefore, these factors were applied as covariates in the association analyses.

The data about the studied SNPs are shown in Table 3. All polymorphisms had MAF $>5 \%$ and did not deviate from the HWE ( $p>0.30$ ). None of the SNPs appeared to be significantly associated with IUGR according to the additive, dominant or recessive models
(Table 4). Haplotype TG defined by rs2234693-rs9340799 of the ESR1 gene (according to the HaploReg (v4.1), the distance between SNPs is $46 \mathrm{bp}, \mathrm{r}^{2}=0.61, \mathrm{D}^{\prime}=1, \mathrm{LOD}>2$ ) was associated with IUGR $\left(\mathrm{OR}=1.94, \mathrm{p}=0.001, \mathrm{p}_{\text {perm }}=0.006\right)$ (Table 5$)$.

The results of the HaploReg (v4.1) analysis suggest that the IUGR-associated SNPs (rs2234693 and rs9340799) have a significant regulatory potential (Table 1 ): they are located in an evolutionarily conserved regions (GERP cons) that have enhancer histone mark (H3K27ac, H3K4me1) in adipose nucleia, and a region of eight regulatory motifs. Allele G of rs2234693 ESR1 decreases affinity to 6 transcription factors - E2A $(\Delta \mathrm{LOD}=-12,0)$, AP-4 $(\Delta \mathrm{LOD}=-11,9), \mathrm{HEN} 1(\Delta \mathrm{LOD}=-11,9), \mathrm{LUN}(\Delta \mathrm{LOD}=-12,0)$, LBP-1 $(\Delta$ LOD $=-1,6)$, RP58 $(\Delta$ LOD $=-11,9)$, and allele $G$ of rs9340799 ESR1 increases affinity to 2 transcription factors Hand $1(\Delta \mathrm{LOD}=11,8)$ and Ets $(\Delta \mathrm{LOD}=4,3)$.

We also studied 26 SNPs, which were linked $\left(r^{2} \geq 0.6\right)$ to the two IUGR-associated polymorphisms (Supplementary Table 1). Among those, rs2077647 (synonymous) was located in an exon and all the others were located in introns. One SNP (rs2077647) was located in an evolutionarily conserved region. Several genetic markers appeared to have a significant regulatory potential. For example, rs2077647 (linked to rs2234693) has a promoter histone

Table 3

The allele and genotype frequencies of the studied SNPs in the case and control groups.

\begin{tabular}{|c|c|c|c|c|c|c|c|c|c|}
\hline Chr & SNP & $\begin{array}{l}\text { Minor } \\
\text { allele }\end{array}$ & $\begin{array}{l}\text { Major } \\
\text { allele }\end{array}$ & $\begin{array}{l}\text { Minor allele } \\
\text { frequency }\end{array}$ & $\begin{array}{l}\text { Number of the studied } \\
\text { chromosomes }\end{array}$ & $\begin{array}{l}\text { Genotype } \\
\text { distribution* }\end{array}$ & Ho & $\mathrm{He}$ & P HWE \\
\hline \multicolumn{10}{|c|}{ IUGR patients $(n=196)$} \\
\hline 6 & rs2234693 & $\mathrm{T}$ & $\mathrm{C}$ & 0.510 & 390 & $50 / 99 / 46$ & 0.508 & 0.500 & 0.887 \\
\hline 6 & rs9340799 & G & A & 0.410 & 388 & $33 / 93 / 68$ & 0.479 & 0.484 & 0.883 \\
\hline 11 & rs484389 & $\mathrm{C}$ & $\mathrm{T}$ & 0.240 & 388 & $11 / 71 / 112$ & 0.366 & 0.365 & 1.000 \\
\hline 11 & rs1042838 & $\mathrm{T}$ & G & 0.169 & 390 & $3 / 60 / 132$ & 0.308 & 0.281 & 0.305 \\
\hline \multicolumn{10}{|c|}{ control group $(n=324)$} \\
\hline 6 & rs2234693 & $\mathrm{T}$ & $\mathrm{C}$ & 0.484 & 632 & $69 / 168 / 79$ & 0.532 & 0.500 & 0.310 \\
\hline 6 & rs9340799 & G & A & 0.388 & 636 & $48 / 151 / 119$ & 0.475 & 0.475 & 1.000 \\
\hline 11 & rs484389 & $\mathrm{C}$ & $\mathrm{T}$ & 0.225 & 636 & $19 / 105 / 194$ & 0.330 & 0.349 & 0.337 \\
\hline 11 & rs1042838 & $\mathrm{T}$ & G & 0.145 & 640 & $7 / 79 / 234$ & 0.247 & 0.248 & 0.824 \\
\hline
\end{tabular}

Note: * minor allele homozygotes/heterozygotes/major allele homozygotes. 
Table 4

Associations of the SNPs of the ESR1 and PGR genes with IUGR.

\begin{tabular}{|c|c|c|c|c|c|c|c|c|c|c|c|c|c|c|}
\hline \multirow[t]{3}{*}{ Chr } & \multirow[t]{3}{*}{ SNP } & \multirow[t]{3}{*}{$\mathrm{n}$} & \multicolumn{4}{|c|}{ Additive model } & \multicolumn{4}{|c|}{ Dominant model } & \multicolumn{4}{|c|}{ Recessive model } \\
\hline & & & \multirow[t]{2}{*}{ OR } & \multicolumn{2}{|c|}{$95 \% \mathrm{CI}$} & \multirow[t]{2}{*}{$\mathrm{P}$} & \multirow{2}{*}{$\begin{array}{l}\text { OR } \\
\text { L95 }\end{array}$} & \multicolumn{2}{|c|}{$95 \% \mathrm{CI}$} & \multirow[t]{2}{*}{$\mathrm{P}$} & \multirow{2}{*}{$\begin{array}{l}\text { OR } \\
\text { U95 }\end{array}$} & \multicolumn{2}{|c|}{$95 \% \mathrm{CI}$} & \multirow[t]{2}{*}{$\mathrm{P}$} \\
\hline & & & & L95 & U95 & & & U95 & L95 & & & & & \\
\hline 6 & rs2234693 & 511 & 1.12 & 0.86 & 1.44 & 0.407 & 1.09 & 0.71 & 1.64 & 0.719 & 1.23 & 0.82 & 1.87 & 0.323 \\
\hline 6 & rs9340799 & 512 & 1.09 & 0.85 & 1.42 & 0.498 & 1.11 & 0.76 & 1.61 & 0.589 & 1.15 & 0.71 & 1.87 & 0.565 \\
\hline 11 & rs484389 & 512 & 1.09 & 0.81 & 1.46 & 0.590 & 1.15 & 0.80 & 1.65 & 0.464 & 0.95 & 0.44 & 2.03 & 0.887 \\
\hline 11 & rs1042838 & 515 & 1.21 & 0.85 & 1.72 & 0.295 & 1.30 & 0.88 & 1.92 & 0.188 & 0.70 & 0.18 & 2.73 & 0.606 \\
\hline
\end{tabular}

All results were obtained after adjustment for covariates.

OR, odds ratio.

$95 \% \mathrm{Cl}, 95 \%$ confidence interval.

Table 5

Associations of the haplotypes with IUGR.

\begin{tabular}{|c|c|c|c|c|c|c|}
\hline \multirow[t]{2}{*}{ Gene } & \multirow[t]{2}{*}{ SNPs included } & \multirow[t]{2}{*}{ Haplotype } & \multicolumn{2}{|l|}{ Frequency } & \multirow[t]{2}{*}{ OR } & \multirow[t]{2}{*}{$\mathrm{P}$} \\
\hline & & & IUGR patients $(\mathrm{n}=196)$ & Controls $(\mathrm{n}=324)$ & & \\
\hline \multirow[t]{4}{*}{ ESR1 } & rs2234693|rs9340799 & TG & 0.143 & 0.080 & 1.94 & 0.001 \\
\hline & rs2234693|rs9340799 & CG & 0.267 & 0.308 & 0.87 & 0.175 \\
\hline & rs2234693|rs9340799 & $\mathrm{TA}$ & 0.368 & 0.404 & 0.93 & 0.332 \\
\hline & rs2234693|rs9340799 & CA & 0.223 & 0.208 & 1.13 & 0.453 \\
\hline \multirow[t]{3}{*}{ PGR } & rs484389|rs1042838 & $\mathrm{CT}$ & 0.162 & 0.139 & 1.21 & 0.300 \\
\hline & rs484389|rs1042838 & CG & 0.081 & 0.089 & 0.90 & 0.651 \\
\hline & rs484389|rs1042838 & TG & 0.757 & 0.772 & 0.93 & 0.645 \\
\hline
\end{tabular}

Note: The results were obtained by the logistic regression analysis with adjustment for covariates; OR - odds ratio, $\mathrm{p}$ - significance level.

mark in 24 tissues, is located in a DNase-1 hypersensitive region in seven tissues, a region of four regulatory motifs (RP58, LUN-1, Znf143, Zfp410), and a binding region for regulatory protein HAE2F1. Polymorphism rs62442056 (linked to rs9340799) is located in a DNase-1 hypersensitive region in 29 tissues, a region of five regulatory motifs (Foxa, Foxi1, CEBPB, TCF12, HDAC2), and a binding region for three regulatory proteins (TCF12, NRSF, SIN3AK20). Polymorphism rs9479130 linked to two loci (rs2234693 and rs9340799) of the ESR1 gene $\left(\mathrm{r}^{2}=1.00\right.$ and $r^{2}=0.61$, respectively) is associated with IUGR. This SNP is located in a DNAase- hypersensitivity region in 24 tissues, a region of two regulatory motifs (ZBTB33, AP-1), and a binding region for three regulatory proteins (TCF12, NRSF, SIN3AK20). Importantly, the loci that are linked to the IUGR-associated SNPs, showed their regulatory effects in organs and tissues related to pathogenesis of IUGR, i.e. ectoderm, mesoderm, and endoderm cultured cells, amnion, placenta, fetal organs (brain, muscle, adrenal gland, etc.), adult organs (pancreas, ovaries, muscle tissue, adrenal gland, adipose tissue, various brain regions (angular gyrus, substantia nigra, hippocampus, germinal matrix etc.), liver etc.) [7].

According to the GTExportal database, variant rs2234693 has the cis-eQTL value and may affect expression of ESR1 in the thyroid glands: allele $G$ of rs2234693 ESR1 is associated with the higher gene expression $\left(\beta=0.13, p=0.000035, p_{F D R} \leq 0.05\right)$. Also, two IUGR-associated SNPs (rs2234693 and rs9340799) are in strong LD with the other cis-eQTL polymorphisms (16 SNPs) affecting ESR1 expression in the thyroid gland (Supplementary Table 2).

\section{Discussion}

In the present study, we report for the first time the associations of two ESR1 gene polymorphisms with IUGR in Russian women from Central Russia: haplotype TG defined by loci rs2234693rs9340799 increased a risk for IUGR (OR = 1.94). According to the HaploReg database (v4.1), allele T of rs2234693 and allele $G$ of rs9340799 increase affinity to the transcription factors E2A, AP-4, LBP-1, HEN1, LUN, RP58, Hand and Ets. The rs2234693 and rs9340799 polymorphisms of the ESR1 gene are located in an evolutionarily conserved regions and have a enhancer histone mark in adipose nucleia. Variant rs2234693 and sixteen polymorphisms linked to rs2234693 and rs9340799 have the cis-eQTL significance and may influence the ESR1 gene expression in the thyroid gland (allele T of rs2234693 decreases the expression of ESR1). In addition, the loci that are linked to the IUGR-associated SNPs (26 polymorphisms), showed their various regulatory effects in tissues and organs related to the pathogenesis of IUGR, fetal and adult organs.

The ESR1 gene (6q25.1-q25.2) encodes an estrogen receptor $\alpha$, a ligand-activated transcription factor consisting of several domains important for hormone binding, DNA binding and activation of transcription. ESR1 and ESR2 (estrogen receptor $\beta$ ) mediate biological effects of estrogen in target tissues. Growth factors can activate ESR1 in the absence of estrogen. Estrogen signaling plays an important regulatory role in the development and function of the reproductive system [20]. In the mouse and rat, disruption of ESR1 causes infertility in both females and males [21]. ESR1 is predominantly expressed in the mammary glands, hypothalamus, pituitary, uterus and ovarian theca cells [22]. Estrogen is a principal regulator of the gonadotropin hormonereleasing hormone $(\mathrm{GnRH})$. GnRH neurons in the hypothalamus synthesize the GnRH peptide, which is a key regulator of the cascade of hormonal events that are necessary for normal sexual maturation and reproductive function [23].

During pregnancy, the primary source of steroid hormones (estrogens and progesterone) is placenta. Studies performed in vivo suggest that placental steroid hormones may be important in driving the changes in glucose metabolism and insulin sensitivity of the mother during pregnancy (play roles in regulating glucose and insulin homeostasis, appetite regulation and lipid handling) [24].

Estrogen stimulates the activation of the insulin-like growth factor 1 receptor (IGF1R) which triggers the activation of the phosphoinositide 3-kinase (PI3K)/AKT pathway for execution an inhibitory phosphorylation of the glycogen synthase kinase 
(GSK-3 $\beta$ ). Inactivation of GSK-3 $\beta$ prevents the inhibitory phosphorylation of cyclin D1 and allows for its nuclear translocation [22]. In addition, IGF1R mediates effects of the insulin-like growth factors IGF-1 and IGF-2, thus promoting fetal and neonatal growth, responding to maternal, fetal and placental signals such as oxygen, hormones, and nutrients [6]. IGF-1 controls fetal growth in response to nutrient availability while IGF-2 stimulates differentiation and placental growth [25]. Further, IGFs control hormone secretion, substrate transport and influence fetal growth either directly by affecting placental nutrient uptake and transport or indirectly by influencing maternal substrate availability [25].

Glucose and amino acid uptakes are stimulated by IGF-1, IGF-2, and trophoblasts [26]. Human IUGR was associated with chronic fetal hypoglycemia [7]. The expression levels of ESR1, progesterone, and insulin-like growth factor 1 in placenta were shown to influence IUGR and gestational age [27].

Previously, loci rs2234693 and rs9340799 associated with IUGR were also reported as candidate for preeclampsia [28-30], age of menarche [31], precocious puberty [32], height at menarche [33], premature ovarian failure [34], endometriosis [35], breast cancer [36], type II diabetes mellitus [37]. Specifically, Molvarec [28] reported the GG genotype of the rs9340799 was associated with a lower risk of IUGR in patients with severe preeclampsia while the homozygous TA haplotype carriers of ESR1 rs2234693 and rs9340799 polymorphisms showed an increased risk of severe preeclampsia. According to the present study results, haplotype TG of loci rs2234693-rs9340799 increased a risk for IUGR (OR = 1.94) in patients without preeclampsia. Although the results of the two studies are somewhat inconsistent, they suggest that allele $G$ of the rs9340799 polymorphism may contribute to pregnancy complications. This assumption gains further support from a recent meta-analysis, which showed that the GG genotype of the ESR1 rs9340799 polymorphism could be a genetic risk factor for severe preeclampsia susceptibility [30].

\section{Conclusion}

Haplotype TG defined by loci rs2234693-rs9340799 of the ESR1 gene was a factor for an increased risk of IUGR (OR = 1.94). Allele T of rs2234693 and allele $G$ of rs9340799 increase affinity to eight transcription factors (LBP-1, AP-4, E2A, HEN1, RP58, LUN, Ets and Hand); allele T of rs2234693 decreases expression of ESR1 in the thyroid gland. The loci linked to the IUGR-associated SNPs have the cis-eQTL value (expression ESR1 in the thyroid gland) and show their regulatory effects in tissues and organs related to pathogenesis of IUGR. The ESR1 gene may contribute to the development of IUGR through the estrogen signaling pathway. However, further studies are needed to verify this assumption.

\section{Declaration of Competing Interest}

The authors declare that they have no known competing financial interests or personal relationships which have, or could be perceived to have, influenced the work reported in this article.

\section{Acknowledgements}

The study was supported by the Concuil of the grants of the President of the Russian Federation (NS-2609.2020.7).

\section{Appendix A. Supplementary data}

Supplementary material related to this article can be found, in the online version, at doi:https://doi.org/10.1016/j.ejogrb.2020.07.045.

\section{References}

[1] Sharma D, Shastri S, Sharma P. Intrauterine growth restriction: antenatal and postnatal aspects. Clin Med Insights Pediatr 2016;10:67-83, doi:http://dx.doi. org/10.4137/CMPed.S40070.

[2] Devaskar SU, Chu A. Intrauterine growth restriction: hungry for an answer. Physiology (Bethesda) 2016;31:131-46, doi:http://dx.doi.org/10.1152/physiol.00033.2015.

[3] Nardozza LM, Caetano AC, Zamarian AC, Araujo [71_TD\$DIFF]Júnior E, et al. Fetal growth restriction: current knowledge. Arch Gynecol Obstet 2017;295:1061-77, doi:http://dx.doi.org/10.1007/s00404-017-4341-9.

[4] Heshmat SH. Intrauterine growth restriction - a review article. Anatomy Physiol Biochem Int J 2017;1:555-72, doi:http://dx.doi.org/10.19080/ APBIJ.2017.01.555572.

[5] Malhotra A, Allison BJ, Castillo-Melendez M, Jenkin G, Polglase GR, Miller SL. Neonatal morbidities of fetal growth restriction: pathophysiology and impact. Front Endocrinol (Lausanne) 2019;10:55, doi:http://dx.doi.org/10.3389/ fendo.2019.00055 Published 2019 Feb 7.

[6] Zhang S, Regnault TR, Barker PL, et al. Placental adaptations in growth restriction. Nutrients 2015;7:360-89, doi:http://dx.doi.org/10.3390/nu7010360.

[7] Priante E, Verlato G, Giordano G, et al. Intrauterine growth restriction: new insight from the metabolomic approach. Metabolites 2019;9:267, doi:http:// dx.doi.org/10.3390/metabo9110267.

[8] Brodsky D, Christou H. Current concepts in intrauterine growth restriction. J Int Care Med 2003;19:307-19.

[9] Horikoshi M, Beaumont RN, Day FR, et al. Genome-wide associations for birth weight and correlations with adult disease. Nature 2016;538:248-52, doi: http://dx.doi.org/10.1038/nature19806.

[10] Warrington NM, Beaumont RN, Horikoshi M, et al. Maternal and fetal genetic effects on birth weight and their relevance to cardio-metabolic risk factors. Nat Genet 2019;51:804-14, doi:http://dx.doi.org/10.1038/s41588-019-0403-1.

[11] Eaves LJ, Pourcain BS, Smith GD, York TP, Evans DM. Resolving the effects of maternal and offspring genotype on dyadic outcomes in genome wide complex trait analysis ("M-GCTA"). Behavr Genetic 2014;44:445-55, doi: http://dx.doi.org/10.1007/s10519-014-9666-6.

[12] Beaumont RN, Warrington NM, Cavadino A, et al. Genome-wide association study of offspring birth weight in 86577 women identifies five novel loci and highlights maternal genetic effects that are independent of fetal genetics. Hum Mol Genet 2018;27:742-56, doi:http://dx.doi.org/10.1093/hmg/ddx429.

[13] Sorokina IN, Rudykh NA, Bezmenova IN, et al. Population genetic characteristics and genetic epidemiological research of candidate genes associations with multifactorial diseases. Res Results Biomed 2018;4:20-30, doi:http://dx. doi.org/10.18413/2313-8955-2018-4-4-0-3 (In Russian).

[14] Reshetnikov E, Zarudskaya O, Polonikov A, et al. Genetic markers for inherited thrombophilia are associated with fetal growth retardation in the population of Central Russia. J Obstet Gynaecol Res 2017;43:1139-44, doi:http://dx.doi. org/10.1111/jog.13329.

[15] Hadlock FP, Deter RL, Harrist RB. Sonographic detection of abnormal fetal growth patterns. Clin Obstet Gynecol 1984;27:342-51.

[16] Ponomarenko, Reshetnikov EA, Altuchova OB, et al. Association of genetic polymorphisms with age at menarche in Russian women. Gene 2019;686:228-36.

[17] Ponomarenko. Selection of polymorphic loci for association analysis in genetic-epidemiological studies. Res Result Med Pharm 2018;2:40-54, doi: http://dx.doi.org/10.18413/2313-8955-2018-4-2-0-5 (in Russian).

[18] Che R, Jack JR, Motsinger-Reif AA, Brown CC. An adaptive permutation approach for genome-wide association study: evaluation and recommendations for use. BioData Min 2014;7:9, doi:http://dx.doi.org/10.1186/1756-0381 7-9.

[19] Ward LD, Kellis M. HaploReg: a resource for exploring chromatin states, conservation, and regulatory motif alterations within sets of genetically linked variants. Nucleic Acids Res 2012;40:D930-4.

[20] Deroo BJ, Korach KS. Estrogen receptors and human disease. J Clin Invest 2006;116:561-70.

[21] Rumi MAK, Singh P, Roby KF, et al. Defining the role of estrogen receptor $\beta$ in the regulation of female fertility. Endocrinology 2017;158:2330-43, doi: http://dx.doi.org/10.1210/en.2016-1916.

[22] Vasquez YM, DeMayo FJ. Role of nuclear receptors in blastocyst implantation. Semin Cell Dev Biol 2013;24:724-35, doi:http://dx.doi.org/10.1016/j. semcdb.2013.08.004.

[23] Ng Y, Wolfe A, Novaira HJ, Radovick S. Estrogen regulation of gene expression in GnRH neurons. Mol Cell Endocrinol 2009;303:25-33, doi:http://dx.doi.org/ 10.1016/j.mce.2009.01.016.

[24] Napso T, Yong HEJ, Lopez-Tello J, Sferruzzi-Perri AN. The role of placental hormones in mediating maternal adaptations to support pregnancy and lactation. Front Physiol 2018;9:1091, doi:http://dx.doi.org/10.3389/ fphys.2018.01091.

[25] Sferruzzi-Perri AN, Owens JA, Pringle KG, Roberts CT. The neglected role of insulin-like growth factors in the maternal circulation regulating fetal growth. J Physiol 2011;589:7-20, doi:http://dx.doi.org/10.1113/jphysiol.2010.198622.

[26] Roos S, Lagerlöf O, Wennergren M, Powell TL, Jansson T. Regulation of amino acid transporters by glucose and growth factors in cultured primary human trophoblast cells is mediated by mtor signalling. Am J Physiol, Cell Physiol 2009;297:723-31, doi:http://dx.doi.org/10.1152/ajpcell.00191.2009. 
[27] Akram SK, Sahlin L, Ostlund E, Hagenäs L, Fried G, Söder O. Placental IGF-I, estrogen receptor, and progesterone receptor expression, and maternal anthropometry in growth-restricted pregnancies in the Swedish population. Horm Res Paediatr 2011:75:131-7, doi:http://dx.doi.org/10.1159/000320466 Epub 2010 Oct 21.

[28] Molvarec A, Ver A, Fekete A, et al. Association between estrogen receptor alpha (ESR1) gene polymorphisms and severe preeclampsia. Hypertens Res 2007;30:205-11, doi:http://dx.doi.org/10.1291/hypres.30.205.

[29] Golovchenko OV. Molecular genetic determinants of pre-eclampsia. Res Results Biomed 2019;4:139-49, doi:http://dx.doi.org/10.18413/2658-65332019-5-4-0-11 (In Russian).

[30] Zhao G, Cai Y, Liu J, Meng T. Association between the estrogen receptor $\alpha$ gene polymorphisms rs2234693 and rs9340799 and severe and mild preeclampsia: a meta-analysis. Biosci Rep 2019;39:, doi:http://dx.doi.org/ 10.1042/BSR20181548 BSR20181548.

[31] Stavrou I, Zois C, Ioannidis JP, Tsatsoulis A. Association of polymorphisms of the oestrogen receptor alpha gene with the age of menarche. Hum Reprod 2002; 17:1101-5.

[32] Luo Y, Liu Q, Lei X, et al. Association of estrogen receptor gene polymorphisms with human precocious puberty: a systematic review and meta-analysis. Gynecol Endocrinol 2015;31:516-21.
[33] Kulik-Rechberger B, Skorupski P, Bogusiewicz M, Miotła P, Rechberger T, Height at menarche is influenced by estrogen receptor alpha gene polymorphisms. J Endocrinol Invest 2010;33:332-8, doi:http://dx.doi.org/ $10.1007 /$ bf03346595.

[34] He M, Shu J, Huang X, Tang H. Association between estrogen receptora gene (ESR1) PvuII $(\mathrm{T} / \mathrm{C})$ and XbaI $(\mathrm{A} / \mathrm{G})$ polymorphisms and premature ovarian failure risk: evidence from a meta-analysis. J Assist Reprod Genet 2015;32:297-304, doi:http://dx.doi.org/10.1007/s10815-014-0393-y.

[35] Li Y, Liu F, Tan SQ, Wang Y, Li SW. Estrogen receptor-alpha gene PvuII (T/C) and $\mathrm{XbaI}(\mathrm{A} / \mathrm{G})$ polymorphisms and endometriosis risk: a meta-analysis. Gene 2012;508:41-8, doi:http://dx.doi.org/10.1016/j.gene.2012.07.049.

[36] Lu X, Li B, Wei JM, Hua B. The XbaI and PvuII gene polymorphisms of the estrogen receptor alpha gene in Chinese women with breast cancer. Zhonghua Wai Ke Za Zhi 2005;43:290-3 (in Chinese).

[37] Ereqat S, Cauchi S, Eweidat K, Elqadi M, Nasereddin A. Estrogen receptor 1 gene polymorphisms (PvuII and XbaI) are associated with type 2 diabetes in Palestinian women. PeerJ 2019;7:e7164, doi:http://dx.doi.org/10.7717/ peerj.7164. 